\title{
Personnel Management Measures for Regional Pharmacies in the Context the Shortage of Skilled Workers Due to Elderly and Demographic Changes
}

\section{A. Changaee (Ali Changaee), E. Kalavsky (Erich Kalavsky)}

SEUC PhD program in Health management and public health, Pharmacist of

Triangulum Pharmacy. Gelnhausen, Deutschland.

\section{E-mail address:}

change48@gmx.de

\section{Reprint address:}

\section{Ali Changaee}

SEUC PhD program in Health management and public health

Pharmacist of Triangulum Pharmacy

Hailer Str. 1663571

Gelnhausen,

Deutschland

Source: Clinical Social Work and Health Intervention

Volume: 11

Issue: 3

Pages: 35 - 40

Cited references: 11

\section{Reviewers:}

Mageswaari Rajoo

Bangkok, Thailand

Gabriela Lezcano

San Francisco, CA, USA

\section{Keywords:}

Regional pharmacies, Demographic changes

\section{Publisher:}

International Society of Applied Preventive Medicine i-gap

CSWHI 2020; 11(3): 35 - 40; DOI: 10.22359/cswhi_11_3_05 C Clinical Social Work and Health Intervention

\section{Abstract:}

The Federal Republic of Germany is currently populated by around 83 million people. By 2050 this number is expected to decrease to around 65 million inhabitants. Thus, the development is assumed to result in an annual net migration gain of 100,000 people. Even with a migration gain of 200,000 people, the number of inhabitants will be reduced to about 70 million. The reason for this is demographic change. While the number of elderly people is constantly increasing, the number of newborns is stagnating. In a scenario with 100,000 people, in 2050 out of every 100 people between 20 and 60 years of age, 
around 80 would be older people over 65 . This problem not only affects the future world of work, but already the current one, because an ageing population not only affects the composition of the labor force, but also the labor market balance.

\section{Introductions:}

The Federal Republic of Germany is currently populated by around 83 million people. ${ }^{1}$ By 2050 this number is expected to decrease to around 65 million inhabitants. Thus, the development is assumed to result in an annual net migration gain of 100,000 people. Even with a migration gain of 200,000 people, the number of inhabitants will be reduced to about 70 million. The reason for this is demographic change. While the
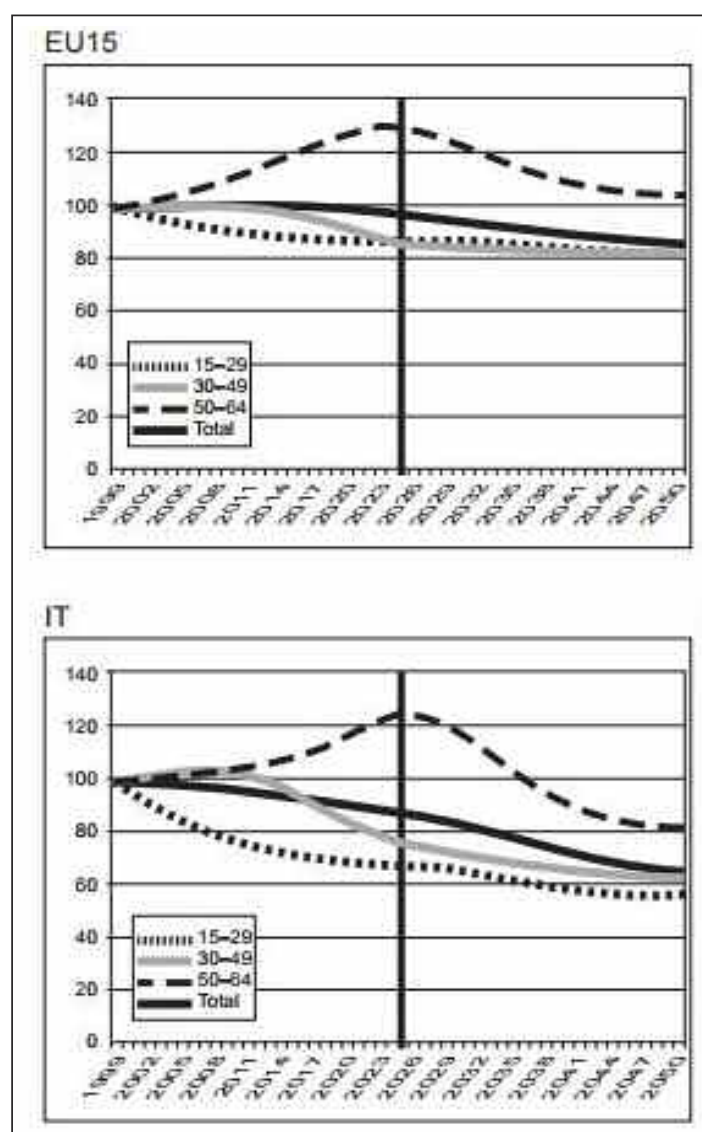

number of elderly people is constantly increasing, the number of newborns is stagnating. In a scenario with 100,000 people, in 2050 out of every 100 people between 20 and 60 years of age, around 80 would be older people over 65 . This problem not only affects the future world of work, but already the current one, because an ageing population not only affects the composition of the labor force, but also the labor market balance. $^{2}$

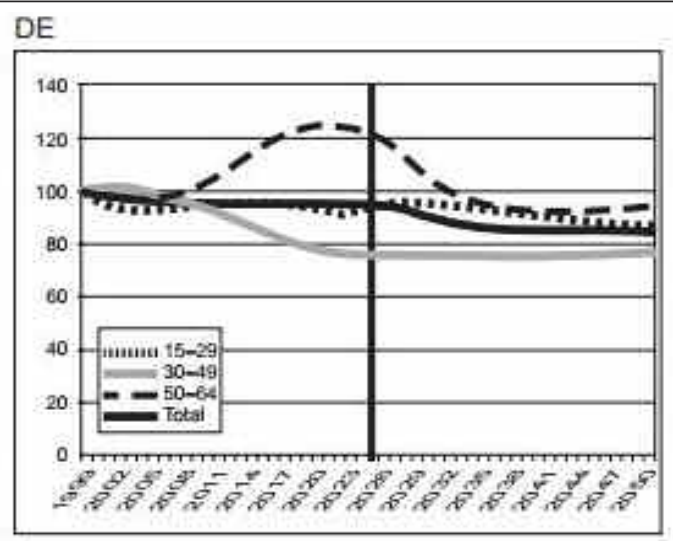

UK

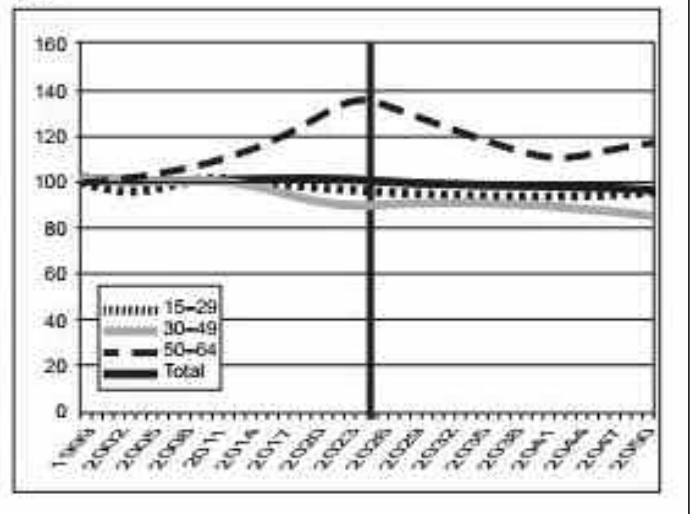

Figure 1: Trends in the size of individual age groups of the working age population in the EU and selected Member States $1999 \pm 2050(1999=100)^{3}$

\footnotetext{
${ }^{1}$ Federal Statistical Office (2019), Population statusd (13.03.2020), https://www.destatis.de/DE/Themen/ Gesellschaft-Umwelt/Bevoelkerung/Bevoelkerungsstand/_inhalt.html [13.03.2020]

${ }^{2}$ Vgl. Kistler/ Hilpert (2001), Effects of Demographic Change on Work and Unemployment, p.5

${ }^{3}$ Kistler/ Hilpert (2001), Effects of Demographic Change on Work and Unemployment, p.6, from Coomans, 2000
} 
The above figure shows the composition of the labor force potential, broken down by age groups between 15 and 64 years, in a forecast up to 2050 for the $15 \mathrm{EU}$ countries, for Germany and, in comparison with the UK and Italy.

This clearly shows that demographic change is not developing in the same way in all countries. This also leads to far-reaching problems in the labor market, especially in the medical and pharmaceutical sectors such as pharmacies. The fact is that the younger a population, the more labor is available. If young people are lacking, there will also be a lack of skilled workers who will be able to move up from training and studies. The know-how that is essential for the economy and for the ability to innovate cannot be made available and pharmacies lack important knowledge. So if young people are missing, the ,stream of new knowledge" provided free of charge to pharmacies by the state-funded education system in the form of new workers may dry up in the long term, and there is simply a lack of „new“ employees. ${ }^{4}$ Conversely, however, „old“ workers who retire and thus can no longer be made available to the labor market will also be lost in the long term. Consequently, pharmacies have also begun to take demographic change into account in order to avoid promoting unemployment and to draw on the knowledge of the older generation. ${ }^{5}$ This rethinking helps to fill vacancies with the generation $50+$, which otherwise would have little chance of being integrated into the labor market. At the same time, pharmacies, but also other companies, are paying more and more attention to adapting the working conditions of the older generation and ensuring appropriate health improvements. ${ }^{6}$ This means that numerous pharmacies and companies are already on a positive path.

\section{Pharmacies and demographic changes}

The question now arises, however, as to what concrete measures pharmacies can develop to counteract the shortage of skilled workers caused by demographic change. This is the challenge facing personnel management. If the term personnel management is viewed globally, then it refers to the way in which managers and supervisors lead and control the personnel - i.e. the entire workforce - in order to ensure the sustainable existence of the company. The term thus refers, more precisely, to ,all measures and decisions of a personnel management nature" which require efficient deployment and are aimed at the development of employees in pharmacies, and thus also defines the objective of personnel management. $^{7}$

Personnel Management thus describes a generic term whose understanding depends on the actual tasks that are assigned to it. For this reason, there is no generally valid definition, but the understanding of the term can be categorized on the basis of the respective point of view. According to this, personnel management is always a part of strategic management and therefore the part that resource personnel deals with. This is also true in pharmacies, where a flatter hierarchy prevails, as there is only the pharmacist and his staff. ${ }^{8}$ Irrespective of this, the pharmacist must also recruit and retain staff. Therefore, personnel development is part of the pharmacists" field of activity. Personnel Development is used in the context of employee recruitment. In the 1970s, the term ,,personnel development" first appeared in German literature in reference to the personnel strategies applied in the USA in the 1960s called „management development“. This term was used in numerous American companies to develop approaches for the systematic and planned employee-related promotion and development of employees. ${ }^{9}$

There is no uniform definition of the term personnel development in the literature. A possible definition according to Bartscher is:

„Personnel development has the basic objective of integrating the individual career and development goals of employees into the general

\footnotetext{
${ }^{4}$ Vgl. Kistler/ Hilpert (2001), Effects of Demographic Change on Work and Unemployment, p.7

${ }^{5}$ Vgl. Kistler/ Hilpert (2001), a.a.O.

${ }^{6}$ Vgl. Kistler/ Hilpert (2001), Effects of Demographic Change on Work and Unemployment 2001, p.11

${ }^{7}$ Scholz (2009), Vahlens Large Personal Lexicon, p.898

${ }^{8}$ Scholz (2009), a.a.O.

${ }^{9}$ vgl. Mudra (2004), Personnel deveopment, p.5
} 
goals of the company and thus creating a first and foremost human resources development can be understood as an in-company training system whose task is to

1. the skills and knowledge of individual employees

2. the cooperation of working groups and teams,

3. a form of organizational development, i.e. to improve problem-solving processes in an organization in the long term. ${ }^{10}$

Human resources development therefore includes all activities and measures that serve the operational and strategic requirements in a pharmacy. Its task is therefore to bring the skills, motivations, actual behavior and abilities into a medium- and long-term agreement. ${ }^{11} \mathrm{~A}$ package of measures plays a central role here. Although these measures often include training measures, these - as various studies show - rarely lead to the desired success. The mix of measures rather makes up the personnel development. Such measures include, for example, the transfer of know-how; optimization of various processes; support through modern technology, such as cash register systems; a targeted cultural change in pharmacies and companies. ${ }^{12}$

Personnel development is conceptually located between organizational development and in-company training. In-company training focuses on the employees, i.e. the individual, whereas organizational development focuses more on the pharmacy itself and puts this as a whole in the foreground. ${ }^{13}$ It also has an economic effect. It is intended to achieve the pharmacy's goals and to take into account and support the individual goals of the employees. ${ }^{14}$

The objectives of the pharmacies always come first and show the direction of the pharmacy. Human resources development is then based on the individual goals of the pharmacy or company, which can change at any time as a result of a new pharmacy management:

If there is an organizational development process in a company, personnel development must align its activities and strategies with the objectives and change efforts defined there. ${ }^{15}$

Personnel development instruments can be differentiated into measures for personnel training, promotion and work structuring. Successful implementation of personnel development depends on all employees being clear about what the company's goals are, because each employee links different goals and interests to the company. The aim of personnel development is therefore also to balance interests by trying to integrate the personal development and career goals of the individual employees into the general goals of the pharmacy. ${ }^{16}$

The tasks of personnel development can be divided into four core objectives ${ }^{17}$

1. definition of development objectives

2. identification of development needs

3. meeting needs

4. control of the achievement of objectives

Finally, the success of the project is then monitored. In concrete terms: analysis of the working atmosphere; tests; performance assessments. ${ }^{18}$

Above all, staff development through motivation is an important aspect of personnel management, because qualified personnel is an important factor in maintaining a pharmacy. The staff should be able to identify with the pharmacy and their superiors and enjoy their work. Therefore, the motivation that an employee brings with him or her also plays an important role. Positively motivated employees are also more willing to commit themselves to the pharmacy, because a constant and positive bond with the workforce should also prevent the migration of important

\footnotetext{
${ }^{10}$ Einsiedler (2003), Organization of personnel develompment, p.5

${ }^{11}$ Vgl. Wickel-Kirsch et al., (2008), Human resource management, p.81

${ }^{12}$ Vgl. Wickel-Kirsch et al., (2008), a.a.O.

${ }^{13}$ Vgl. Wickel-Kirsch et al., (2008), a.a.O.

${ }^{14} \mathrm{Vgl}$. Becker (2002), Human resource management, p.492

${ }^{15}$ Brockermann (2006), Personnel development manual, p.13

${ }^{16}$ Jung (2006), Human resource management, p.246

${ }^{17} \mathrm{Vgl}$. Jung (2006), Human resource management, p.258

${ }^{18}$ Vgl. Jung (2006), Human resource management, p.258
} 
know-how carriers. Various terms are used in literature and in company practice to describe the concept of staff loyalty. Common expressions such as identification, integration, loyalty, employee retention, but also English terms such as attraction, commitment, relationship, retention or staff retention express that employers want to encourage employees to perform and stay with the company using various strategies. ${ }^{19}$

Demographic change in particular makes it increasingly important for pharmacies to present themselves as an attractive employer to current and future employees in order to retain skilled staff and managers and to attract new employees. This requires not only just the right personnel management and personnel development. In addition, pharmacies have to make use of incentive systems which increase \&/or maintain staff motivation. This includes:

Employee retention [...] all measures of a company which are aimed at positively shaping both the behavioral intentions and the actual behavior of an employee towards an employer or his performance in order to stabilize or expand the relationship with this employee for the future. ${ }^{20}$

Such measures include, for example:

- Financial support for employees

- Health and safety at work

- Flexible organization of working time

- Regular performance reviews

- Professional development

However, personnel commitment can also relate solely to securing strategically important knowledge resources by storing them in so-called knowledge systems. ${ }^{21}$

In reality, however, this only applies if, on the one hand, the basic needs of the staff are met and, on the other hand, if the incentive systems are also tailored to the workforce.

\section{Conclusion}

A lack of incentive systems is not necessarily a reason for employees to resign, but it does help - especially on a material level - to give employ- ees reasons to stand up for their pharmacy. Certainly, it cannot be claimed that the success of staff retention depends solely on incentive systems, but they do help to secure staff, provided that the pharmacy, in principle, is healthy. In this case, pharmacy culture structures and personnel recruitment are considered healthy. ${ }^{22}$ Especially in the future, the labor force, i.e. human capital, will be of vital importance, as it is an important prerequisite for the long-term success of pharmacies. In order to be able to ensure the long-term success of a pharmacy, it is important that the needs and expectations of the employees are recognized and fulfilled. With regard to material incentive systems, such as bonuses, it can be stated that non-cash or cash bonuses are basically permanent and contribute a great deal to employee loyalty. The reason for this is the fact that individual performance is thus rewarded, but on the other hand the annual success of the pharmacy can also be passed on to the employees. This seems to make sense especially from the aspect of maintaining motivation, but also for reasons of fairness. The topic of health also represents an important incentive for employee satisfaction. The more health offers (e.g. yoga, relaxation exercises or work-life-balance strategies) are made possible, the more likely it is that employees will bind themselves to the pharmacy because they are satisfied with their work - despite stress.

Particularly in recent years, health has become one of the most important topics in current health policy, but also of numerous companies, pharmacies and medical practices. Due to demographic developments and the ongoing structural and value changes in society, health is taking on a new dimension and is becoming increasingly important, but above all valuable. Health is no longer just a personal good, but a common good that must be protected. Only those employees who work in a healthy pharmacy are prepared to remain loyal to it and do not migrate. By healthy, we do not mean physical well-being, but rather the structure, pharmacy culture and the employee-employer relationship. For this reason,

\footnotetext{
${ }^{19}$ Vgl. Homburg / Bruhn (2008), Loyalty management, p.8

${ }^{20}$ Homburg / Bruhn (2008), a.a.O.

${ }^{21}$ Vgl. Homburg / Bruhn (2008), Loyalty management, p. 8

${ }^{22}$ Vgl. Homburg / Bruhn (2008), Loyalty management, p. 8
} 
the topics of personnel development and retention play a central role, especially in personnel management. Politicians have recognized this development and are attempting, through legislation and accompanying political and social discussions, to emphasize the importance of health and thus make pharmaceutical professions more attractive. Additional bonuses, through pharmacies or the pharmaceutical sector in general, create incentives to attract or retain employees in the long term.

\section{References:}

1. BARTSCHER A CH (2008) Personnel development and older workers: challenges to an age-appropriate personnel policy. Paderborn: European university publisher.

2. BECKER M(2002) Personnel Develompnet. (3rd, update and revised editioin) Stuttgart: Schafer-Poeschel.

3. BROCKERMANN R (2006) Personnel Development Manual: The Practice of Personnel Education, Personnel Promotion and Work Structuring. Stuttgart: Schafer-Poeschel.

4. EINSIEDLER H (2003) Organization of personnel development: strategically align, plan precisely, control effectively. (2nd, revised edition). Neuwied: Luchterland Verlag.
5. HOMBURG CH, BRUHN M (2008) Customer loyalty management. An introduction to the theoretical and pracitcal problems. In: Homburg, C./Jung, Hans (2006): Personalwirtschaft. (7th, revised edition). Munich: Oldenbourg Verlag.

6. JUNG H (2008) Human Resources. (8th edition). Munich: Oldenbourg Verlag.

7. KISTLER E, HILPERT M (2001) Effects of demographic change on work and uneployment. In: From Politics and Contemporary History B 3-4.

8. MUDRA P (2004) Personnel development integrative design of gorporate learning and change processes. Munich: Verlag Franz Vahlen.

9. SCHOLZ CH (2009) Vahlens Large Personal Lexivon. Munich: Verlag Franz Vahlen.

10. WICKEL-KIRSCH J, MATTHIAS K E (2008) Human resources management: Basic of human resource work in companies. Wiesbaden: Gabler.

11. STATISTISCHE BUNDESAMT (2019) Population status (13.03.2020). Available online on: Https://www.destatis.de/DE/Themen/Gesellschaft-Umwelt/Bevoelkerung/Bevoelkerungsstand/_inhalt.html [13.03.2020]. 